\title{
The Quality of Doctoral Training and Employability of Doctorate Holders: The Views of Doctoral Candidates and Junior Researchers
}

\author{
Filomena Parada and John Peacock
}

\section{Introduction}

In the past decade, a number of issues, such as the growth in the number of doctorate holders, and the inclusion of the 'third cycle' in the Bologna process, contributed to transforming doctoral education in Europe (AAUP 2009; Sursock and Smidt 2010). The number of permanent academic or research staff has not kept pace with the growth in doctoral candidates. The doctorate can no longer be regarded as training for an academic career, and ever more doctoral candidates have to seek alternative careers.

The question then arises as to whether or not the process of completing a doctoral degree is, or can be, valuable to the non-academic sector, to society or to the individual doctorate holder (LERU 2010, 2014). Doctoral training must ensure that doctorate holders are better equipped to pursue non-academic careers, that those considering pursuing a doctorate are aware of the situation and the realities of the academic career path, and that the non-academic sector understands the purpose and value of the doctorate.

These are issues of pressing concern to EURODOC, The European Council of Doctoral Candidates and Junior Researchers, which advocates for an improvement

Disclaimer All official positions and other statements from EURODOC can be found on EURODOC's website: www.eurodoc.net. Statements made in this article which are not found on the website must be considered those of the authors alone and not official positions of EURODOC.

F. Parada $(\square) \cdot$ J. Peacock

EURODOC, The European Council of Doctoral Candidates

and Junior Researchers, Brussels, Belgium

e-mail: filomenaparada@gmail.com

J. Peacock

e-mail: vicepresident@eurodoc.net

(C) The Author(s) 2015

A. Curaj et al. (eds.), The European Higher Education Area,

DOI 10.1007/978-3-319-20877-0_38 
in the quality of development opportunities available to researchers. EURODOC represents both doctoral candidates (DCs), those researchers who are working towards a doctoral degree, and junior researchers (JRs), the larger group that includes all researchers who are not yet fully independent (European Commission 2011). EURODOC works to inform policy makers and other stakeholders of the situation facing early career researchers (ECRs).

In order to fulfil its role, EURODOC annually surveys its members to learn about the situation in different countries across Europe, and gathers other input on various issues from its members on a regular basis. In 2011, EURODOC published the results of EURODOC Survey I, a major survey of 8900 doctoral candidates across Europe (Ates et al. 2011). The survey shed light on a number of the issues mentioned above.

In this paper we will review the results of the survey, and EURODOC's other internal surveys and policy statements, with respect to these topics. We will discuss the issues this raises and make suggestions concerning:

1. The promotion of quality and the improvement of quality assurance in doctoral training and supervision;

2. How to ensure a successful transition from being a doctoral candidate to a doctorate holder. Specifically, the need to ensure that doctoral training programmes enhance the competencies necessary to succeed outside academia, and that employers, especially in the non-academic sector, understand and recognise the value of the doctorate.

\section{EURODOC Survey I: Background}

According to recent EUROSTAT data, in 2011 there were nearly 750,000 doctoral candidates in the EU-27 (EUROSTAT 2014). The number of new doctoral graduates during the last decade increased almost $60 \%$ (Doherty and Chasége 2013). In OECD countries, the number of doctoral degrees being awarded rose by $38 \%$ between 2000 and 2009 (Auriol et al. 2013). Between 2005 and 2010, the total number of R\&D personnel measured as full-time equivalent (FTE) grew on average $2.6 \%$ a year in the EU-27 (EUROSTAT 2013).

These numbers not only show the recent expansion of higher education systems, but also make more visible the situation of DCs and doctoral holders, especially in what concerns the structure, purpose, relevance, and cost of the doctorate. Additionally, the growth in doctoral training raises numerous questions concerning ECRs employment.

In 2008, EURODOC in cooperation with INCHER launched an online Europe-wide survey focusing on the situation of DCs and JRs (Ates et al. 2011). For EURODOC, the survey constituted the perfect means for identifying the main issues affecting ECRs across Europe, and for collecting evidence-based information capable of influencing political decision-making. 
With the survey, EURODOC intended to develop a database of information on the exact circumstances of DCs and JRs working in Europe, specifically concerning (1) their real situation when it comes to employment circumstances, social benefits and overall working conditions, and (2) the differences between European countries, cultures and models of doctoral training, and what can one learn from such differences.

\subsection{Sampling and Procedures}

Survey participants comprised all kinds of researchers working in Europe that were in the process of acquiring, or had recently acquired, their doctoral degree. Participants conducted their research in universities, public research centres, industry, or the private research sector. DCs from more than 30 countries answered the survey. However, only data from 12 countries could be declared statistically significant: Austria, Belgium, Croatia, Finland, France, Germany, Norway, Portugal, Slovenia, Spain, Sweden, and the Netherlands.

\subsubsection{Sample}

The final sample comprised 7561 participants. Respondents held the status of students enrolled in doctoral programmes or of academic and research assistants working on their doctoral degree (or equivalent). Efforts were made to match respondents with the general population, in terms of variables such as gender, field of study and academic status.

$70-90 \%$ of the respondents reported being between 26 and 35 years of age, although in some countries 23-31\% declared being older than 36. Most survey participants had no work experience prior to their doctoral training, some had work experience in the academic sector, and others in the private or public non-research sector. Sciences (e.g., physics, biology) were the most common fields in which participants were conducting their research, while social sciences, business and law were the second most common.

Most respondents lived in civil partnership, regardless of the official nature of that arrangement. The lowest rates of single respondents came from Belgium, while France had the highest rates. The majority of the respondents had no children.

\subsubsection{Data Collection and Data Treatment Procedures}

Procedures were chosen in order to guarantee data comparability, and their potential generalisation. A cross-sectional design using an internet-based survey was used, which ensured a quick delivery by simultaneously contacting a large number of respondents, and covering a wide geographical area. Online data collection took place from December 2008 to May 2009. 
The questionnaire included 77 questions and took about 30 min to complete. It included questions about qualification requirements, career paths, funding schemes, models of training and supervision, working conditions, mobility, and the outcomes of scientific work.

Some trends in participants' answering patterns can be seen as an indicator of ECRs employment situation, work conditions and access to social benefits. However, caution is required in order to avoid an over-interpretation of results. Analyses were directed towards description, and not towards interpretation.

\section{EURODOC Survey I: Findings}

Only survey findings pertaining to the topics addressed by the present work will be taken into consideration. Therefore, we selected rather specific results, and focused on overall results instead of country or gender specific comparisons. Additional information coming from other (internal) sources of information (e.g., EURODOC's annual questionnaire, policy papers) will be used to complement and reinforce survey findings and conclusions.

\subsection{Type of Supervision and Training Opportunities: The Perceptions of Doctoral Candidates and Junior Researchers}

Chapter D of the survey report focused on training and supervision, and its findings shed light on two critical questions: Do doctoral researchers have access to training opportunities when they need or require them? and Do they consider the supervision they receive adequate? Training opportunities were defined in the broadest possible sense. They may refer to, for example, taking courses on specific subjects focusing on the theories or methods required to do the research, as well as on research ethics. They could also refer to the acquisition or development of diverse skills such as transferable skills, and language or ICT skills. Information from chapter E concerning degree structure and DCs rights is also included.

\subsubsection{Access to Training}

Respondents usually reported having received training during their doctoral degree. However, the proportion of 'no' answers wasn't negligible, reaching 20-30\% or higher (Fig. 1). No information was collected on respondents' assessment of the quality or the type of training received.

One of the most remarkable things the data revealed concerned the diversity in the level of information respondents had about time frames for thesis completion. 


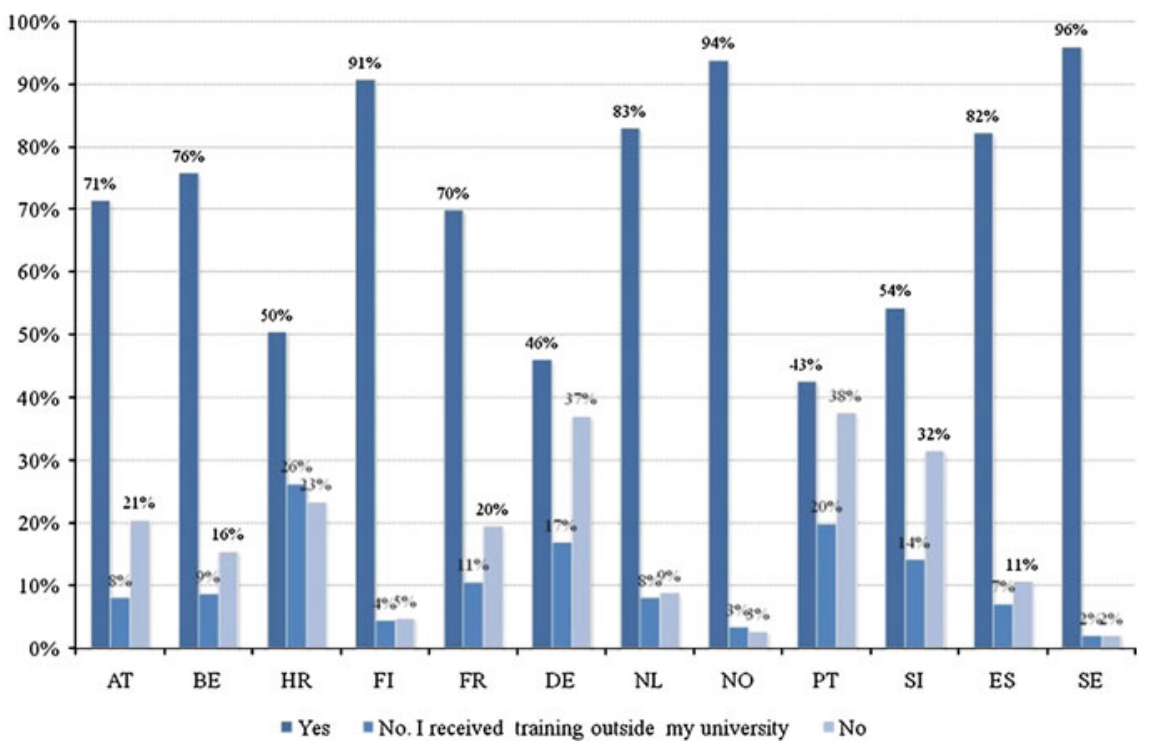

Fig. 1 Did you receive any kind of training (e.g. courses) at your university during your doctorate? (By country). ${ }^{*} \mathrm{~N}=6611$, valid percentages, valid $\mathrm{n}$. Source EURODOC data set (December 2010)

Although most countries appeared to have regulations establishing minimum and maximum completion times, some exceptions were found. For example, while a high percentage of respondents in Slovenia revealed that deadlines exist, $23 \%$ said that a maximum time does not exist, so long as the situation is authorised by the supervisor.

In some countries, the large majority of respondents mentioned not knowing if such minimum time requirements existed (Fig. 2). Similar results were obtained when asking participants if they were aware of the existence of a maximum time frame for thesis completion and, if such a time frame existed, what it would be.

No information was collected allowing to better understand differences in time frames for doctorate completion. The diversity characterising the ways in which doctoral degrees are operationalised (e.g., institutional types, legal frameworks, disciplines, academic and scientific cultures) helps to account for these findings. The same applies to data collected through EURODOC's annual questionnaire. There is a huge variability in situations depending on country, region, university or type of doctoral programme. For example, some DCs are expected to teach, and, depending on the type of programme, they are expected to take courses, while for others these are not requirements. More information is needed to better understand this variability and how it impacts time frames given by institutions.

Consequently, there is no such thing as a typical DC, doctoral holder or doctoral programme (Halse and Mowbray 2011). This situation, although having the advantage of leading to convergence without standardisation within the European 


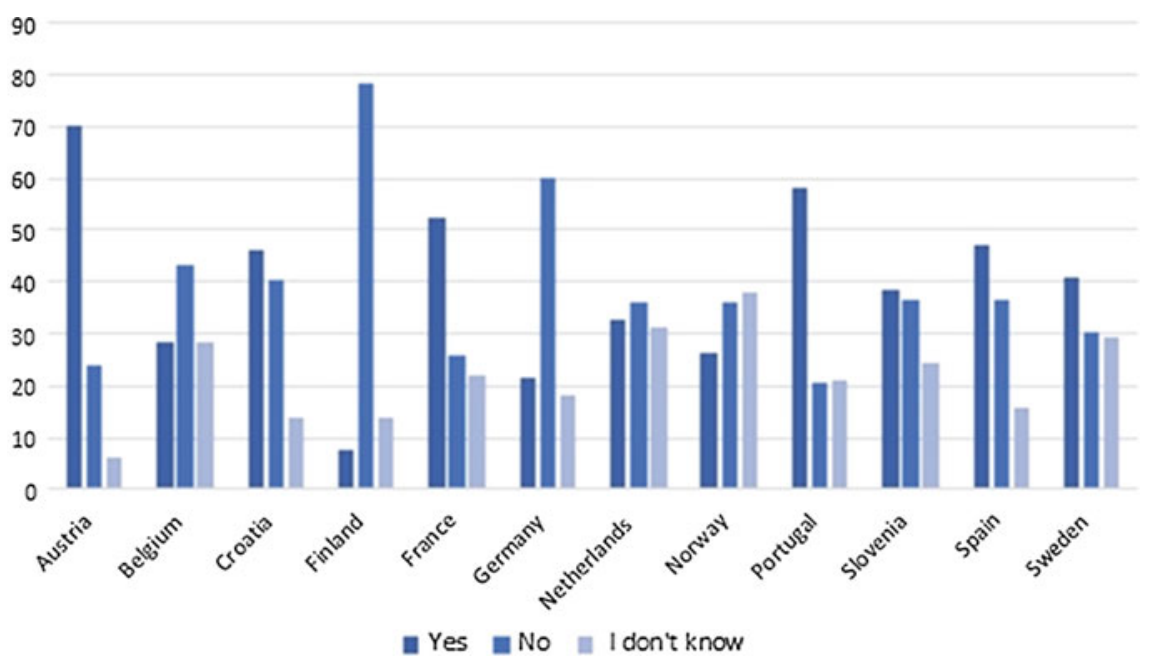

Fig. 2 Is there a minimum required time for completing your doctorate? (By country). $* \mathrm{~N}=5865$, valid percentages, valid n. Source EURODOC data set (December 2010)

Higher Education Area (EHEA) and the European Research Area (ERA), challenges stakeholders' ability to differentiate between programmes, degrees specificities or DCs profiles. The same seems to apply to DCs' ability to know and read the system.

Further information is required (i) to better understand why so many DCs seem to be unaware of the structure of their degree, and (ii) concerning the proportion of DCs that complete their doctorate within the allocated time frame. According to information provided by EURODOC's member organisations, there is either no statistical data available, or the resources they have point to somewhat low completion rates. A clearer understanding of why this happens and how it relates to DCs' knowledge about their responsibilities and rights would also be interesting.

\subsubsection{Access to Training: General Recommendations}

Understanding the structure and the value of the doctorate, in particular the benefits to the doctorate holder, gets complicated when the doctoral degree is such a diverse thing. This is true not only for DCs starting their doctoral training, but also for employers outside academia looking to understand how they should consider the DC's experience. Of course, diversity may itself be useful and no one proposes a one size fits all approach. Making strict rules dictating the structure of all doctorates is not always reasonable.

Even if doctorates differ, it is still important that a clear knowledge of its structure exists. What to expect from one's training, and what career paths to pursue as a doctorate holder are not always clear. Many DCs start a doctorate hoping to pursue an academic career, and many JRs seem to persist in that same hope. Thus, 
in order to better prepare prospective DCs for the realities of a research career, clearer and more complete information on what the job involves should be provided. This includes such basic information as the time frames for completing the degree.

Not knowing time frames and activities attached to the completion of a doctorate is indicative of a larger problem of a lack of information. We recommend that full and complete information should be available from the beginning. Where doctoral positions are advertised there should be clear information on the content, duration and other conditions of the job. New DCs can be provided with further information, making the full conditions of their relationship with the university and the requirements to complete the doctorate transparent. This could be done through personal meetings, mentorship, and other initiatives such as welcome days for new DCs.

\subsubsection{Training Opportunities}

Across Europe, educational systems and training practices at the doctoral level tend to be diverse. The nature of the programmes varies considerably, with some being mandatory, some being voluntary and some being a mixture of both. This varies even within institutions as individual programmes are often constructed differently. The same applies to the type of training programmes offered. For example, while training on 'theories of my subject' was predominantly mandatory, training in 'methods of my subject' and 'transferable skills' was predominantly voluntary.

Overall, survey respondents considered that their training contributed to the improvement of their skills in six of the seven domains assessed: theories/methods of my subject, transferable and language skills, research ethics, and information technology. For theories and methods of my subject, a clear increase in perceived level of competency was identified. Responses changed from a majority at the average level to a majority at a high to very high level.

Teaching skills were the exception. Although some increase in participants' sense of competency could be noticed, responses tended to remain at average. This appears particularly relevant when considering that some universities routinely require DCs to teach.

Satisfaction with the training received varies across countries and types of skills. Although some exceptions were observed, most respondents felt satisfied or moderately satisfied with their training. However, for 'transferable skills' the picture is more diverse: some participants are satisfied, while others feel only moderately satisfied. In other cases (e.g., Croatia, Spain) participants responses were scattered, being difficult to clearly identify a response pattern.

Again, EURODOC's annual questionnaire points to a large diversity of situations, and to the impact such diversity has on the types of doctoral programmes offered. However, following the Bologna process, a number of reforms began to be introduced, aimed at reviewing the structure of doctoral degrees and the quality of training (e.g., holding a Masters degree as a prerequisite for a doctoral program; 
establishing a more structured or standardised approach to doctoral training by creating doctoral schools; listing skills or learning outcomes DCs are expected to develop; connecting national education systems with the European Qualifications Framework; implementing monitoring mechanisms).

Previous findings and EURODOC's internal data document not only doctoral programmes' variability, but also DCs and JRs own recognition that they need a thorough and broad set of skills. This agrees with LERU's (2010) recommendations that researchers' training should be directed towards the development of a unique set of high level skills, and determined by the interplay between professional research experience and personal development.

However, access to training opportunities and satisfaction with training appear to be areas in need of improvement. Training, either formal (through organised programmes) or informal (done on the job), is of importance for ECRs, allowing them to develop the skills they need for their careers (LERU 2014). Thus, the quality and breadth of the training should not be neglected.

\subsubsection{Training Opportunities: General Recommendations}

Our data indicates that a diverse range of training opportunities are available to DCs, but this varies between countries and institutions. To improve the overall standard of doctoral training, more work needs to be done to assess the effectiveness of individual training programmes. Survey responses indicate varying levels of quality. For some types of training this varies by country, while for others there appears to be no pattern.

Results suggested that where training was provided, the mandatory component was more focussed on developing knowledge needed to successfully conduct research (such as 'theories of the subject'), while other skills that might promote personal development or be more useful outside of academia were more often voluntary. There is thus a need to ensure that doctoral training is not exclusively focussed on research training, but takes a broader view. Doctoral training adjusted to today's knowledge society should provide ECRs with a context for the development of their research that is international, interdisciplinary, and intersectoral.

More information is needed about which institutions promote DCs training, what is the structure of the programme (e.g., courses to be taken, duration of training) and DCs perception of the quality and usefulness of the training. The same applies to understanding the types of programmes and courses DCs consider most relevant to their career development, within or outside academia. In particular, the types of skills they consider most useful and would like to see improved.

\subsubsection{Supervision Agreement, Quality and Feedback}

In the early stages of their training, DCs often benefit from a more structured relationship with their supervisors, which can be established by means of a formal 
agreement, where the roles of each party are defined. Most survey respondents indicated having some form of agreement. The only country in which this was not the norm was Germany, while in Austria almost the same amount of participants responded positively and negatively (Fig. 3).

However, in many countries up to $20 \%$ of respondents indicated that they were not aware of the possibility to have such a contract. Different explanations can be provided for the previous results: perhaps participants' inexperience or lack of knowledge about university regulations accounts for the percentage of 'I don't knows'. The same applies to the possibility of no such normative regulations being foreseen at the regional or national level. Nonetheless, it appears that recommendations included in the European Charter of Researchers and Code of Conduct for the Recruitment of Researchers (European Commission 2005) are not being followed.

Responses indicated that the majority find their supervisors supportive or very supportive when planning or reviewing their training. All DCs regarded the feedback they got from supervisors as useful or very useful. This usefulness in feedback indicates the importance of providing good supervision, and of having a supervisor who is available to offer advice. If taken together with answers to previous topic (supervision agreement), these findings point to the importance of building positive, constructive relationships between supervisors and supervisees. However, as a rule, supervisors don't seem to offer (appropriate) career guidance to their supervisees (Puljak and Sharif 2009). Also, we need to know more about ongoing debates concerning the (dis)advantages of team supervision (instead of individual one) as a

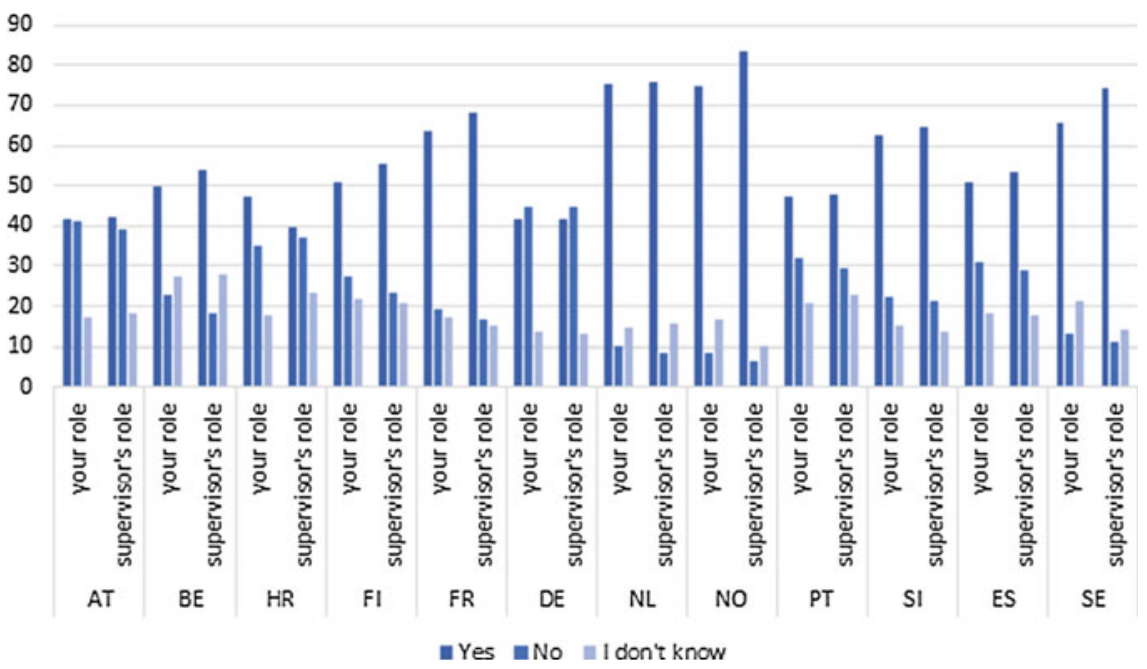

Fig. 3 Does any kind of formal, binding agreement exist between you and your supervisor (such as a contract or university regulations) that defines your role/the role of your supervisor? (By country). $* \mathrm{~N}=6241$ (your role)/6223 (supervisor's role), valid percentages, valid n. Source EURODOC data set (December 2010) 
preferable option, and of supervisors having an international profile, and how it affects ECRs.

The notion of improving support for early career faculty is not always well received by senior faculty (Foote 2010). To some extent, it is possible to consider that survey responses reflect a similar understanding. While participants appeared to be satisfied with supervisors' level of expertise in their field of research, a mixed pattern of answers was identified for the degree in which supervisors were able to provide regular guidance and advice (Fig. 4).

One thing that may help explain these results is variability in the ratio of supervisors to supervisees (Fig. 5). Some countries reported an average of 1-2 supervisees to supervisors, while others reported an average of 8-9. A small percentage of respondents said that their supervisor supervised 20 or more supervisees. These findings support Foote's (2010) assertion that factors such as the department in which ECRs work or had their first job, and the advisor picked can have a substantial impact on ECRs career, either enhancing or hindering their access to (learning, employment) opportunities.

Supervision agreement, quality and feedback: General recommendations

Recognising the relevance of supervision for ECRs, EURODOC published a charter for supervision and training (EURODOC 2004). Many of the recommendations here can be traced to that document.

Supervision is an important component of a successful doctorate, but the quality of supervision varies greatly. Although respondents generally reported average to excellent supervision, a sizeable percentage reported their situation as poor. Supervisors were generally rated most highly in terms of their ability to help DCs implement their research, but much more poorly for the general support and guidance in, for example, helping to develop a career plan.

In order to improve the overall quality of supervision, more focus should be placed on training supervisors on the needs of ECRs. We recommend continuous,

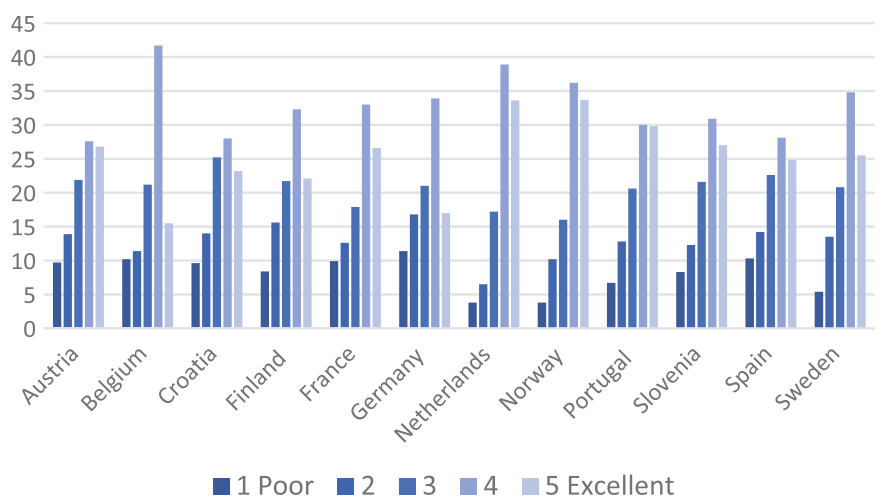

Fig. 4 How do you feel your supervisor is fulfilling his/her role in providing regular guidance? (By country). $* \mathrm{~N}=6149$, valid percentages, valid $\mathrm{n}$. Source EURODOC data set (December 2010) 


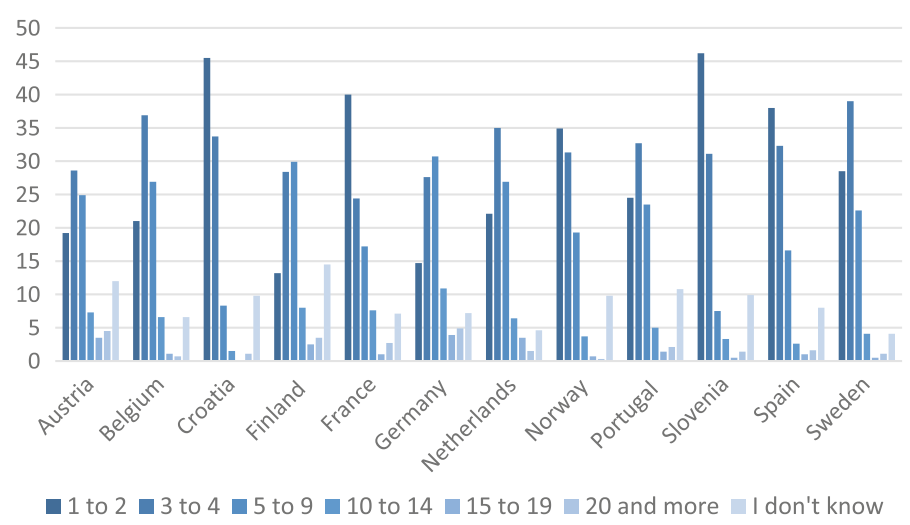

Fig. 5 How many DCs does your supervisor supervise in total? (By country). ${ }^{*} \mathrm{~N}=6323$, valid percentages, valid n. Source EURODOC data set (December 2010)

mandatory training be provided for supervisors, and mentoring for new supervisors. Having such regular training will help to ensure that standards are maintained.

One other important consideration is the number of supervisees each supervisor is expected to supervise. More supervisees will affect the supervisors' ability to understand the individual needs of each supervisee and the specifics of their work. The workload of supervisors needs to be monitored, and should allow sufficient time to regularly meet with each person they supervise, discuss their individual situation, and provide feedback and guidance.

A plan for supervision and monitoring of supervision can be built into research funding where employment of a DC or JR is envisaged. We recommend that a formal written agreement is drawn up, which spells out the relationship between supervisor and supervisee, and the expectations of each party. An agreement should also be reached on a feasible plan for the project, one that details a timetable and key (research, future career) objectives to be achieved. Such a plan should take into account all other (teaching, administrative) obligations the ECR may have.

\subsection{Current Research Framework and Future Career Paths: Assessments Made by Doctoral Candidates and Junior Researchers}

Chapter F of the survey report aimed to understand the outputs DCs and JRs were expected to produce as a result of their research, and the different types of activities they engaged in during their training. Information from other chapters (e.g., chapter $\mathrm{B}$ on career paths) will be included and complemented with data collected from EURODOC's questionnaire. This will provide us with additional insights into participants' assessments of their current framework as researchers, and expectations towards their future careers. 


\subsubsection{DCs and JRs Status and Funding}

At least two thirds of the respondents declared having a full-time student status. However, in several countries participants also declared being in paid employment, often with a fixed-term employment contract (Figs. 6 and 7). No information was provided on the type of employment, only on current employment status. Also, a large proportion of respondents said some of the work they were doing was not part of their contract.

From EURODOC's annual questionnaire, it is possible to conclude that a huge variety of situations and funding schemes exist across Europe. DCs and JRs can access funding by applying to many different sources (e.g., funding schemes promoted by universities or other research promoters, funding schemes promoted by funding organisations or agencies, fellowships, self-funding through an employment contract within or outside academia). Additional information is required to better understand the specifics of each of these funding sources, as well as their benefits and disadvantages for DCs and JRs, especially concerning their current living and family situation and their careers.

Respondents' answers suggest that it is not clear for them if they are allowed to use findings from their research or how this would be possible, regardless of being in a collaborative research project or not. Nonetheless, about one third of the respondents engaging in collaborative research projects referred not being able to use their findings (Fig. 8). Not only does this goes against what the Charter and Code recommends, but it also may have some negative impact on DCs and JRs career prospects. Being able to disseminate one's research results is a crucial means of gaining visibility inside and outside academia.

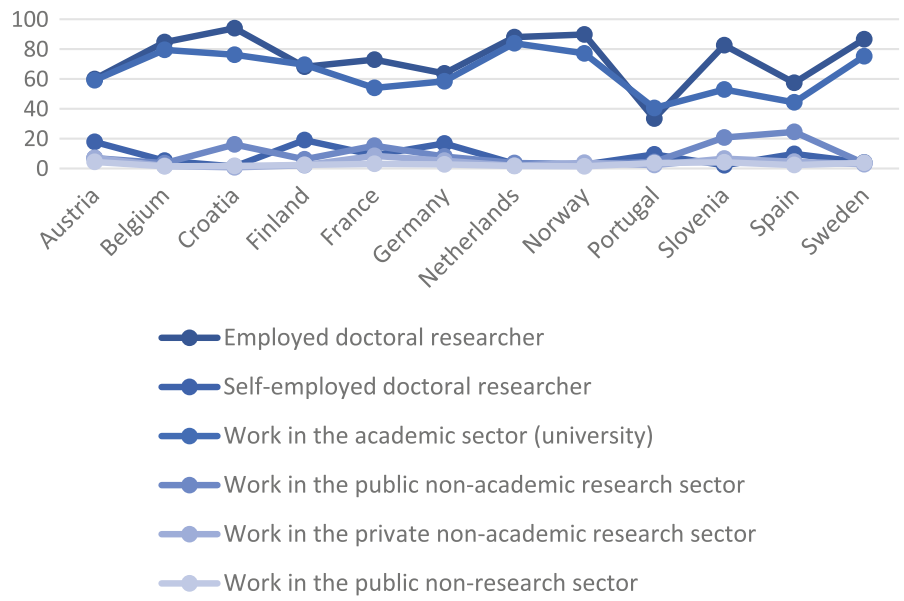

Fig. 6 What is your current employment situation as a doctoral researcher? (By country; multiple response-Part I). $* \mathrm{~N}=7031$, valid percentages, valid n. Source EURODOC data set (December 2010) 


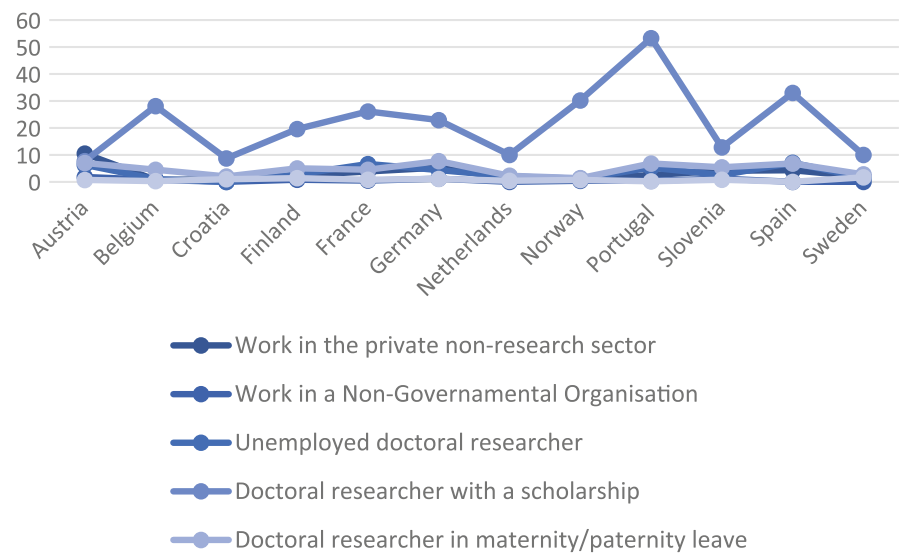

Fig. 7 What is your current employment situation as a doctoral researcher? (By country; multiple response-Part II). ${ }^{*} \mathrm{~N}=7031$, valid percentages, valid n. Source EURODOC data set (December 2010)

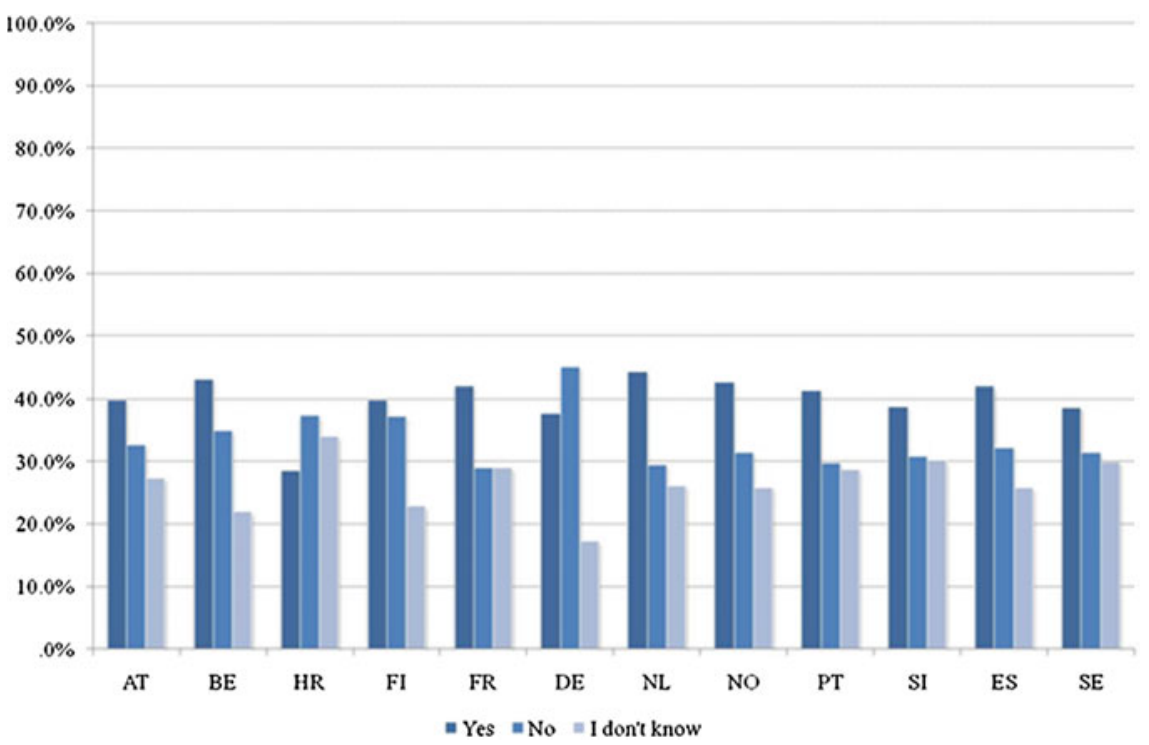

Fig. 8 If you are in a collaborative project, are there clear agreements on using the project findings? (By country). ${ }^{*} \mathrm{~N}=3470$ valid percentages, valid $\mathrm{n}$. Source EURODOC data set (December 2010)

The high rates of survey participants declaring no awareness of the Charter and Code (Fig. 9) may help to better understand these findings, which are largely corroborated by answers to EURODOC's annual questionnaire. Data collected through the questionnaire portrays a mix of situations when it comes to our member 


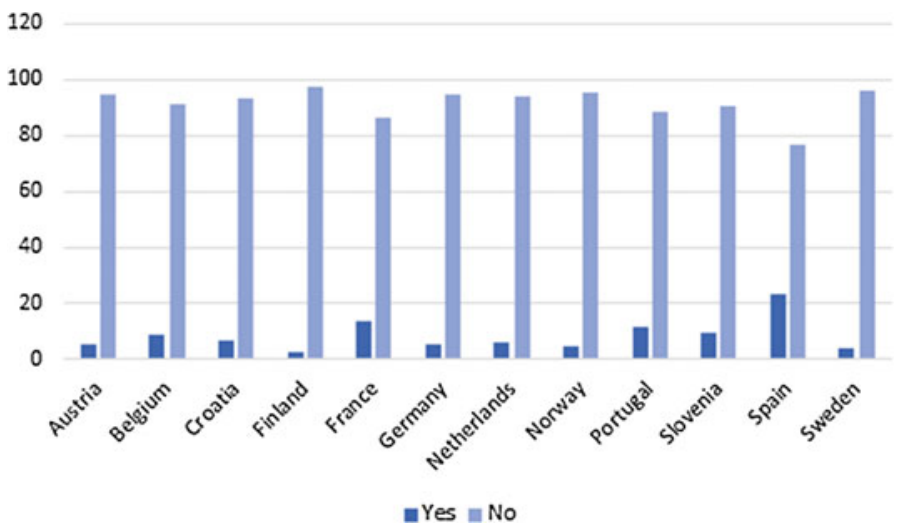

Fig. 9 Are you aware of the European charter for researches/code of conduct for the recruitment of researchers? (By country). ${ }^{*} \mathrm{~N}=7024$, valid percentages, valid n. Source EURODOC data set (December 2010)

organisations' knowledge or actions taken towards its dissemination, and assessment of the steps given by their countries' institutions concerning its implementation. Lack of resources (human or otherwise) is one of the explanations provided.

\subsubsection{DCs and JRs Status and Funding: General Recommendations}

We recommend that more be done to raise awareness of the Charter and Code among researchers themselves. The Charter and Code has previously been endorsed by EURODOC and its implementation is one of the organisation's stated goals. The actual implementation of these widely agreed upon principles would go some way to help improving the general conditions of researchers. Raising awareness of the principles in the Charter and Code among researchers would work to empower them to seek their implementation in their own institutions, and so contribute to a more effective construction of ERA and of the EHEA.

The high numbers of doctorate holders produced by the system can lead to a situation where ECRs are seen as an expendable resource. Within academia there are not enough jobs for everyone, and renovation is taking place at a slow pace. Thus, of vital concern is the need to recognise DCs as full staff members of universities and research organisations, full members of the academic community, and have their rights recognised accordingly. In other words, DCs should be acknowledged as researchers and as professional workers, with a clear employment contract offered to all. The work DCs and JRs are expected to do should be made clear, and should be agreed upon, at the beginning.

The increase in doctoral graduates and programmes has made it necessary for doctorate holders to consider other, non-academic, employment pathways. This can 
be challenging for employers, who often find it difficult to differentiate between different programmes, doctoral degrees and candidates. Thus, to have their experience as researchers formalised as work could be highly beneficial.

\subsubsection{Activities and Academic Work Outputs}

The survey indicated that DCs were engaged in many different activities, from doing research, to teaching, to administrative work. The amount of time spent on each activity varied greatly among respondents. For example, some participants reported spending more than $21 \mathrm{~h}$ per week on teaching, while others reported doing no teaching at all. Data also indicate much diversity in the conditions of each of these activities, including whether or not DCs were entitled to pay for teaching.

Taking courses is another activity that usually occupies respondents' time. Like for teaching, there are participants reporting more than $21 \mathrm{~h}$ per week of courses to attend, and others that don't have to attend courses. The same response pattern was observed for administrative tasks. Often, these activities have no relation to the doctoral research.

Engaging in other tasks or activities (planning new research projects, choosing collaborators, writing grants, determining authorship, organising panel/conferences, deciding about institutional policy) may also take a considerable part of participants weekly work hours (more than $21 \mathrm{~h}$ per week). Nonetheless, except for planning new research projects, most participants declared not being involved in this type of activity. As for writing grants, although a mixed pattern of responses prevails, the number of participants answering 'no' outweighs the 'yeses'.

The pattern of activity engagement just described was cross-sectional to the whole sample. In other words, most DCs are required or expected to perform a wide variety of activities while doing their training. The nature, quantity, and type of engagement required also vary significantly, not only across countries but also between specific research contexts. Their non-engagement in activities such as writing grants, organising panels/conferences, or deciding about institutional policy may be understood either as a good practice example (so that DCs may commit entirely to their thesis), or as a lost opportunity (for networking, for acquiring skills and experience).

The majority of respondents declared allocating either an average or a substantial amount of time to writing their thesis; the same applies to research relating to their thesis. However, when it comes to publications a large majority of respondents report not having yet delivered a single output (e.g., articles in national/international journals with or without peer review, articles in proceedings, scientific monographs, reviews, online articles, patent applications). It would be interesting to understand why participants' overall productivity was so low. Perhaps the amount of time required by all the other activities prevents them from devoting more time to publishing. Perhaps this has to do with the fact that at the time of data collection many of our respondents were at the early stages of their doctorate, not having yet 
enough material or expertise to produce a publication. More information is required in order to answer these and other questions our findings highlight.

Overall, the findings described above seem to portray a rather encouraging picture of the type of experience DCs have during their doctorate. DCs appear to have the opportunity to acquire expertise in several domains directly related to their future careers, while combining it with the work on their research or thesis/dissertation. However, no information was provided on the degree of autonomy DCs and JRs were given for determining the scope, direction and progress of their research. In addition, differences seem to exist between DCs in terms of the amount of time devoted to each of the activities, with some having access to a variety of experiences and opportunities, while others don't. The same applies to several other aspects determining their general working conditions (e.g., pay, access to resources and facilities, opportunities for networking and career advancement, access to funding).

\subsubsection{Activities and Academic Work Outputs: General Recommendations}

General agreement exists around the idea that the system is complex and heterogeneity (of situations across countries, universities, fields of research, funding schemes) prevails, so before starting to take any specific measures a more comprehensive understanding of its functioning and organisation is needed. As mentioned, there are several topics in which more information is needed (e.g., DCs and JRs autonomy; total amount of weekly work hours by country, field of research, university/department; the way in which these findings relate to previous findings, such as quality of supervision or knowledge about/existence of a formal agreement with supervisor).

However, available information also allows us to make several recommendations, much in line with what we have suggested elsewhere. For example, the crucial role of the supervisor and of the quality of supervision ECRs have access to. Not only is it important to provide DCs and JRs with a variety of experiences to expand and diversify their skills, but it is also necessary to ensure that the amount of time allocated to these other activities does not jeopardise ECR's ability to be productive. Thus, it is important to establish clear, explicit agreements (or contracts) at the onset of the doctorate or of the post-doctorate, which would allow DCs and JRs to know precisely what they are expected to do. These agreements should also ensure that the activities and outputs DCs and JRs are expected to produce are relevant not only to their supervisor or department, but also to their own career.

More relevance should be given to aspects such as opportunities for advancement, level of responsibility and the degree of independence offered to ECRs. To a large extent, such aspects determine DCs and JRs satisfaction with their jobs. As our findings seem to indicate, DCs and JRs are often expected to put in long working hours. At the same time, it is not uncommon for them to experience limited autonomy in carrying out research projects and some difficulties in accessing 
resources (e.g., accommodation and access to facilities, training budgets, conference funding and related occupational extras; representation on email networks, websites and publicity materials; opportunities for (internal) promotion and progression, including pay). Taken together, all of these aspects contribute to a lack of attractiveness of research careers in Europe. In order to improve the attractiveness of research careers, these issues need to be addressed.

\subsubsection{Expectations Towards the Doctorate}

The survey asked participants to choose which sector of the labour market they wished to work in after finishing their doctorate, with multiple choices being allowed. The most popular option in all countries was to work in the academic research sector, followed by the non-academic public research sector, and the private research sector. Far fewer respondents were interested in the non-research sector, with careers in the military being the least appealing. In most countries at least $50 \%$ of respondents suggested they would consider a non-academic research career.

A majority of respondents believed that their doctorate would increase their employment opportunities in the academic sector 'to a very high extent'. However, respondents were more modest when asked whether or not they believed the doctorate would help their employment prospects outside of academia (Fig. 10).

The sizeable minority of respondents (Fig. 11) reported that they had chosen to pursue a doctorate after turning down a higher paid job. This might be explained by how respondents answered questions on the advantages they expected from completing a doctoral degree. Survey participants were asked this question in a number of different contexts, and asked to rate their perception on a scale ranging from 'to a

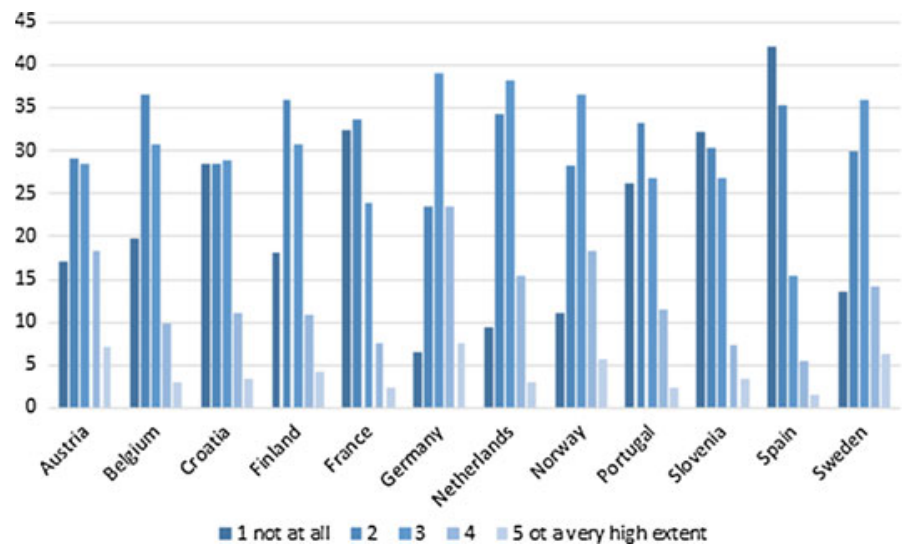

Fig. 10 The doctorate increases my job opportunities in the private non-research sector (By country). $* \mathrm{~N}=6563$, valid percentages, valid $\mathrm{n}$. Source EURODOC data set (December 2010) 


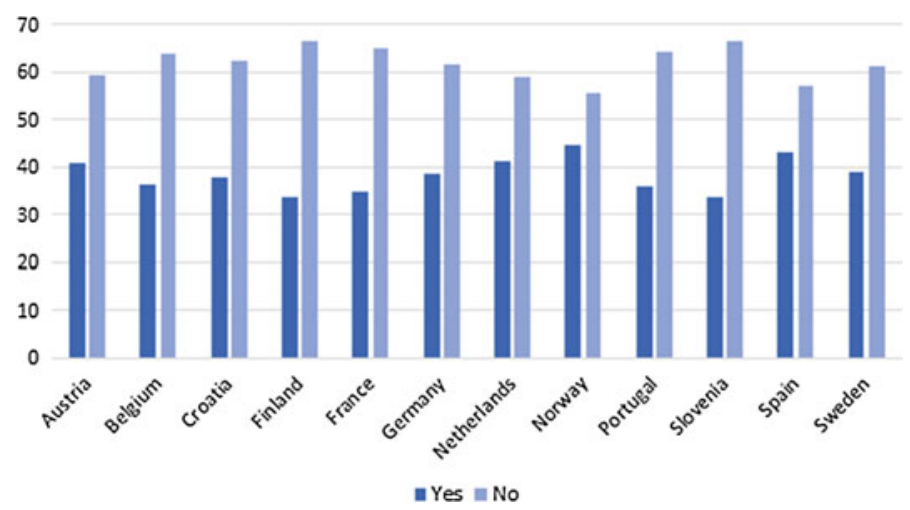

Fig. 11 Did you choose to do a doctorate while turning away better paid job opportunities? (By country). $* \mathrm{~N}=6786$, valid percentages, valid $\mathrm{n}$. Source EURODOC date set (December 2010)

very high extent', to 'not at all'. When asked whether or not 'largely independent of the disposition of the work...' was perceived as an advantage, very few respondents (at most $5.3 \%$ in Spain) responded not at all. Most respondents suggested they thought the doctorate would provide them with some advantage, particularly concerning the 'opportunity to pursue research.

To pursue research inside academia appears to be respondents' preferred career option. However, when looking into their answers to other questions of the survey, it is possible to conclude that, to some extent they are open to other career paths, including the pursuit of a non-academic research career. Perhaps this is an indication of some pragmatism on their part, especially if considering the precariousness of working conditions offered to ECRs, in particular inside academia, and the overall lack of employment opportunities recent doctorate holders are confronted with. Nonetheless, it is somewhat surprising how many of our participants directed their career expectations towards a research career within academia, which may point to their lack of knowledge and unrealistic expectations towards the doctorate, including its protective value against unemployment.

\subsubsection{Expectations Towards the Doctorate: General Recommendations}

It seems clear that the doctorate is largely viewed as a positive thing for an individual's career, and this seems true for most possible careers. However, the realities of that career might not be so obvious to many ECRs. The percentage of researchers expressing an interest in an academic career varies from $68.4 \%$ in Germany to $83.2 \%$ in Croatia. These high levels may indicate that information on the difficulties in pursuing an academic career are not being made clear to DCs. These findings could be said to show that the doctorate is still largely being 'mis-sold' and 
that more needs to be done to change people's perceptions of what a doctorate is, and what being awarded one means.

We recommend more effort be made to provide career guidance to DCs and to JRs, to have them think about their future plans during the course of their doctorate. Most universities will already have some form of career service for undergraduate students, which can also be made to work for ECRs. These services would likely benefit from a clearer understanding of the needs/wants of doctoral candidates, and the realities of the labour market for doctorate holders. The same could be said about some of the senior staff working in academia and academia itself. Academia and the labour market ECRs are confronted with today are very different from that faced by senior researchers in their time. However, it doesn't always seem that academic structures and culture have managed to adjust to today's realities.

\section{Conclusions}

Using data from EURODOC's survey and other internal sources, the previous paragraphs have described some aspects of the general situation in which ECRs find themselves. They point to a number of aspects concerning DCs' and JRs' general situation that should be improved in each one of the topics we covered: (i) perceptions and overall satisfaction with access to training, training opportunities, supervision agreement, quality and feedback; (ii) assessments of own status and funding, activities and academic work outputs, as well as expectations towards the doctorate (e.g., type of employment, employment prospects).

The recommendations made in this paper are general ones, and further development is necessary. However they already point to a number of issues policy makers and other relevant stakeholders should take into consideration when implementing reforms aimed at promoting quality and improving quality assurance in doctoral training, as well as ensuring a successful transition from being a doctoral candidate to a doctorate holder.

What is clear in many instances is that more data on the conditions ECRs are working in, and their general perceptions of their work, working conditions and future careers, is needed. EURODOC Survey I also focussed almost entirely on DCs, and did not survey JRs. Thus, it is necessary to also assess their perceptions of the situation they are in. This is what EURODOC intends to do with a future survey. We believe that a follow up survey examining some of these issues in more depth, including the situation of JRs, would prove very valuable.

Open Access This chapter is distributed under the terms of the Creative Commons Attribution Noncommercial License, which permits any noncommercial use, distribution, and reproduction in any medium, provided the original author(s) and source are credited. 


\section{References}

AAUP, American Association of University Professors. (2009). Reforming doctoral education in Europe academe, January-February. Retrieved from http://www.aaup.org/article/reformingdoctoral-education-europe\#.VB3aGxaKUmE

Ates, G., Höllander, K., Koltcheva, N., Kirstč, S., \& Parada, F. (2011). EURODOC survey I: The first EURODOC survey on doctoral candidates in twelve European countries-descriptive report. Brussels: EURODOC, The European Council of Doctoral Candidates and Junior Researchers.

Auriol, L., Misu M., \& Freeman A. R. (2013). Careers of doctorate holders: Analysis of labour market and mobility indicators. In OECD (Ed.), OECD Science, Technology and Industry Working Papers. Paris: OECD Publishing.

Doherty, R., \& Chasége, L. (2013). Researchers' report 2013-final report. Retrieved from http:// ec.europa.eu/euraxess/index.cfm/general/researchPolicies

EURODOC. (2004). Supervision and training charter for early stage researchers. Retrieved from http://www.eurodoc.net/wp-content/uploads/2012/10/20040331_supervision_and_training.pdf

European Commission. (2005). The European charter for researchers and the code of conduct for the recruitment of researchers. http://ec.europa.eu/euraxess/pdf/brochure_rights/ am509774CEE_EN_E4.pdf

European Commission. (2011). Towards a European framework for research careers. Brussels: European Commission.

EUROSTAT. (2013). Science, technology and innovation in Europe. Retrieved from http://epp. eurostat.ec.europa.eu/cache/ITY_OFFPUB/KS-GN-13-001/EN/KS-GN-13-001-EN.PDF

EUROSTAT. (2014). R\&D personnel-statistics explained. Retrieved from http://epp.eurostat.ec. europa.eu/statistics_explained/index.php/R_\%26_D_personnel\#Doctoral_students

Foote, K. E. (2010). Creating a community of support for graduate students and early career academics. Journal of Geography in Higher Education, 34, 7-19.

Halse, C., \& Mowbray, S. (2011). The impact of the doctorate. Studies in Higher Education, 36, 513-525.

LERU, League of European Research Universities. (2010). Doctoral degrees beyond 2010: Training talented researchers for society Position Paper, March. Retrieved from http://www. leru.org/files/publications/LERU_Doctoral_degrees_beyond_2010.pdf

LERU, League of European Research Universities. (2014). Good practice elements in doctoral training advice paper no. 15. Retrieved from http://www.leru.org/files/publications/LERU_ AP_15_Good_practice_elements_in_doctoral_training_2014.pdf

Puljak, L., \& Sharif, W. D. (2009). Postdocs' perceptions of work environment and career prospects at a US academic institution. Research Evaluation, 18, 411-415.

Sursock, A., \& Smidt, H. (2010). Trends 2010: A decade of change in European Higher Education EUA, European University Association: Trends Reports. Retrieved from http://www.eua.be/ publications/eua-reports-studies-and-occasional-papers.aspx 